Research Article

\title{
Application of Fuzzy Analytical Network Process and VIKOR Model in Foreign Trade Supplier Selection
}

\author{
Tsung-Xian Lin,, Xiao Wang $\mathbb{D}^{1,2}{ }^{1,2}$ Zhong-huan $W u^{1,2}$ and Che-Chang Chang ${ }^{1}$ \\ ${ }^{1}$ School of Management, Guangzhou Huashang College, Guangzhou 511300, China \\ ${ }^{2}$ Institute for Economic and Social Research, Huashang College, Guangzhou 511300, China \\ Correspondence should be addressed to Xiao Wang; zhiji67220007@163.com
}

Received 4 August 2021; Accepted 31 August 2021; Published 20 November 2021

Academic Editor: Sang-Bing Tsai

Copyright (C) 2021 Tsung-Xian Lin et al. This is an open access article distributed under the Creative Commons Attribution License, which permits unrestricted use, distribution, and reproduction in any medium, provided the original work is properly cited.

\begin{abstract}
The technology in Taiwan's panel industry is changing fast. However, after the financial tsunami and the increased price for raw materials, enterprises' abilities to select suppliers and purchase have great influences on plan implementation. Therefore, with the prevailing issues of supply chain management, how to evaluate and select appropriate suppliers has become a very important topic for enterprises. Depending on customers' needs, the requirements for suppliers vary from industry to industry. On this basis, this study summarizes and analyzes the literature on supplier selection to develop the supplier selection criteria, constructs the hierarchical network architecture by an expert interview, and proposes a complete supplier evaluation model by the fuzzy theory and network analysis. This study shows that the order of the important dimensions is as follows: performance evaluation, customer service, technology and competitiveness, cost benefits, and architecture, and the most important criterion is quality. Finally, the material suppliers of backlight modules in the panel industry are taken as the examples and ranked by VIKOR, based on their merits and demerits, to help related industries to understand their current advantages and disadvantages according to the selection results obtained by the fuzzy analytical network process and improve the gap between their actual situations and enterprises' expectations and thus enhance their competitiveness.
\end{abstract}

\section{Introduction}

Since the panel industry and DRAM industry were introduced in Taiwan, under the "Two Trillion and Twin Star Development Program," the government has made great efforts to guide enterprises and conditionally prohibited the industries from entering mainland China. However, since the financial storm, sales have not been as high as expected. In addition to the existing labor costs and process optimization, materials are also the main reason for panel price fluctuations.

The majority of panel materials are backlight modules, liquid crystals, polarizers, ICs, and PCBs. In terms of cost, if the backlight modules require repair, the suppliers will repair and replace components on-site. The main materials to be replaced are membranes and light bars, which are reusable. However, for panel manufacturers, the material cost of backlight modules accounts for about $20-25 \%$ of the total cost, indicating the importance of raw materials to the panel industry. As raw material supply and management are the main parts to enhance competitiveness and reduce costs, many panel manufacturers integrate or form strategic alliances with upstream backlight module plants to maximize benefits.

At present, panels are moving towards smaller sizes, and backlight modules are moving towards lightweight and high-quality LEDs. In the manufacturing process, panel and backlight industries have an interdependent cooperative relationship; thus, material shortages in the manufacturing process will affect secondary and tertiary material manufacturers, as they cannot deliver on time, resulting in losses. In this situation, it will take more time to find temporary partners, quality and efficiency will be at risk, and there may be customer complaints. Hence, selecting appropriate suppliers can improve the requirements and management of enterprise profits and quality, create overall profit, and 
reduce operating costs, which helps enterprises to maintain their competitive advantages in the industry.

Therefore, the purposes of this paper are to construct a supplier selection model, calculate the relative weights of all dimensions and criteria by the fuzzy analytical network process, and conduct ranking by the VIKOR method, in order to determine the optimal compromise solution. The construction process is as follows: firstly, the initial selection items are collated and prepared through literature review and analysis, and the hierarchical network architecture is constructed by the expert questionnaire; secondly, according to the study requirements, the research methods of the supplier selection, such as fuzzy numbers and linguistic variables, the fuzzy analytical network process, and the VIKOR ranking method, are introduced; finally, backlight modules are taken as the example and analyzed to verify the feasibility of the model, and then conclusions and suggestions are made.

\section{Literature Review}

2.1. Supplier Management. Suppliers mainly provide the materials and resources required by downstream firms to facilitate the upstream firms' ability to produce specific products and services, which are known as subcontractors in the industry. Subcontractors can offer real-time or long-term on-site supply and cooperate with enterprises to supply materials. Secondly, the main task of procurement departments is to provide materials for production departments to facilitate the delivery of after product storage, and they are responsible for purchasing raw materials, substituting materials, fixtures, and equipment, and bargaining. Hence, raw material suppliers are herein referred to as the suppliers. Since enterprises have no components, services, or raw materials, the first task in supplier selection is to build supply chains in order to establish enterprises' supplier management.

2.2. Supplier Selection Criteria. Purchasing abilities are important for enterprises to execute plans as scheduled; therefore, to maintain fixed material storage and control costs, enterprises must have operational procedures to achieve standardization and execution. However, the decision of supplier selection is not a single-level problem but a multilevel problem. In addition, when selecting suppliers, in order to reduce costs, enterprises will consider cooperation plans with multiple suppliers, which raises their ability to bargain and brings more benefits to the enterprises as there is room for discount and bargaining in the case of large procurement volumes.

Supplier selection was first studied by Dickson [1]; among 170 questionnaires, the top 3 evaluation factors were "product quality," "price," and "delivery time," with the usage percentage above $90 \%$. According to that study, more than $1 / 3$ of the enterprises collected and reviewed suppliers' performance and conditions to provide a basis for subsequent supplier selection, and the evaluation factor of "quality" accounted for a considerable proportion. Then, Weber et al. [2] analyzed the literature on panel industry suppliers from 1967 to 1990, based on Dickson's evaluation criteria, and showed that his evaluation criteria included suppliers' locations and smooth production and delivery.

Dowlatshahi [3] developed three models for enterprises to evaluate suppliers, including tactics, strategy, and cooperation, which established criteria that allow enterprises to select suppliers at high, medium, and low levels and designed four supplier restriction factors. Barbarosoglu [4] discussed supplier selection criteria from "supplier execution evaluation," "enterprise structure and manufacturing ability evaluation," and "quality system," which led to a difference from traditional supplier selection dimensions. Finally, this paper compares the supplier selection indices in the domestic and foreign literature, and the results indicate that "quality" is mostly considered during selection, followed by "delivery time" and "price," as shown in Table 1.

\section{Research Design}

\subsection{Research Method}

3.1.1. Fuzzy Numbers and Linguistic Variables. The fuzzy sets theory [5], as proposed by Professor Zadeh in 1965, emphasizes that human thought, reasoning, and perception regarding surroundings are fuzzy to some extent; thus, it is necessary to describe the advantages, disadvantages, and situations of things with fuzzy logic to make up for the shortcomings of the traditional two-valued logic in the linguistic description of things. The fuzzy sets theory is mainly used to deal with fuzzy situations and shows the membership degree of fuzzy zones with membership functions, where the values are between 0 and 1 .

The triangular fuzzy number $\widetilde{A}$ is represented by $(l, m$, $u$ ), and $l \leq m \leq u$, as shown in Figure 1. Its membership function $\mu_{\bar{A}}(x)$ is defined as follows [6].

$$
\mu_{A}(x)= \begin{cases}(x-l) /(m-l), & l \leq x \leq m, \\ (u-x) /(u-m), & m \leq x \leq y, \\ 0, & \text { otherwise. }\end{cases}
$$

Secondly, the words in natural languages should be the values of linguistic variables [7-9], and words such as \{strongly disagree, disagree, fair, agree, strongly agree can be used to express the evaluators' feelings of an evaluation value. Linguistic variables can duly express these subjective judgments and be used to process undefined or fuzzy information.

In addition, it supposes that there are 2 fuzzy numbers: $\widetilde{A}_{1}=(11, \mathrm{~m} 1, \mathrm{u} 1)$ and $\widetilde{A}_{2}=(12, \mathrm{~m} 2, \mathrm{u} 2)$, and $\mathrm{c}$ is a constant. According to the characteristics of fuzzy numbers and the extension principle $[10,11]$, the fuzzy numbers are calculated, as follows:

$$
\begin{aligned}
\widetilde{A}_{1} \oplus \widetilde{A}_{2} & =\left(l_{1}+l_{2}, m_{1}+m_{2}, u_{1}+u_{2}\right), \\
\widetilde{A}_{1} \otimes \widetilde{A}_{2} & =\left(l_{1} l_{2}, m_{1} m_{2}, u_{1} u_{2}\right), \\
c \otimes \widetilde{A}_{1} & =\left(c l_{1}, c m_{1}, c u_{1}\right), \\
\widetilde{A}_{1}^{-1} & =\left(l_{1}, m_{1}, u_{1}\right)^{-1}=\left(\frac{1}{u_{1}}, \frac{1}{m_{1}}, \frac{1}{l_{1}}\right) .
\end{aligned}
$$


TABLe 1: Supplier evaluation indices in Taiwan and abroad.

\begin{tabular}{lcc}
\hline Ranking & Taiwan's studies & Foreign studies \\
\hline 1 & Quality & Quality \\
2 & Delivery time & Delivery time \\
3 & Price & Price \\
4 & Financial condition & Location \\
5 & Cooperation relationship & Equipment and capacity \\
6 & Customer structure & Technique \\
7 & Production technology & Organization and management \\
8 & Flexibility & Fame and status \\
9 & Response speed & Financial condition \\
10 & Research and development technology & Past performance \\
\hline
\end{tabular}

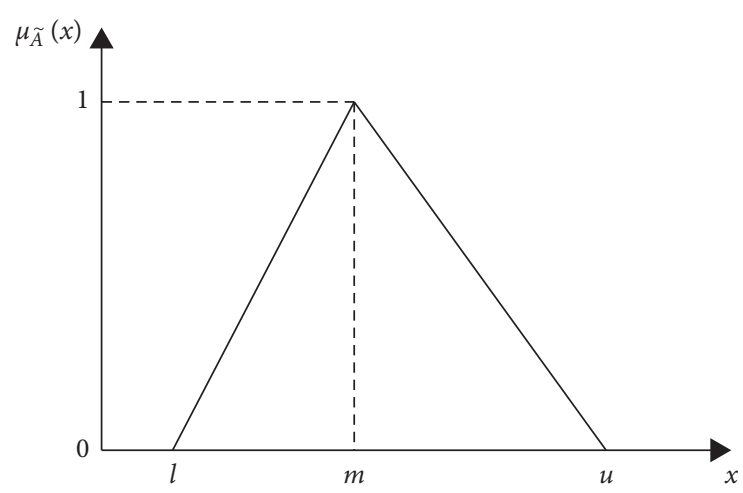

Figure 1: Triangular fuzzy number.

3.1.2. Fuzzy Analytic Network Process. The analytic network process (ANP) was proposed by Saaty in 1996. As problems become more complex, the correlation among elements at different levels also become more complex and is no longer a simple linear relationship. If the traditional analytic hierarchy process (AHP) is used for decision-making analysis, its independent assumptions and oversimplified hierarchies will easily lead to errors in the evaluation results, which will increase the risk of errors by decision makers and reduce decision-making quality [12].

However, as an extension of the analytic hierarchy process, the analytic network process is presented as a nonlinear network structure, meaning it adds interdependence among the various elements of the linear structure of the traditional analytic hierarchy, which can only apply a unidirectional hierarchical relationship, and considers the feedback mechanisms. In terms of fundamental assumptions, except the assumptions that "the hierarchical structure is a directed network" and "elements are independent of each other" in the analytic hierarchy process, other assumptions are suitable for the network analytic hierarchy process.

Secondly, in reality, criteria and programs in many decision-making problems often interact with each other; thus, according to the network analytic hierarchy process, decision makers can clarify the relationships among criteria in the decision-making problems of a complex network structure, and the risk of decision-making errors can be reduced. When making decisions, the human mind is usually subjective and uncertain; hence, it is difficult for evaluators to make evaluations and measurements with precise numbers. Zimmermann [11] argued that the fuzzy theory can be added to the decision-making process in order to effectively formulate questions and overcome the subjective and undefined characteristics of the obtained information. Büyüközkan et al. [13] argued that applying the fuzzy theory to the network analytic hierarchy process can effectively process nonquantitative and incomplete information and thus provide decision makers with solutions to subjectivity and fuzziness in evaluations in an uncertain decision-making environment.

Hence, the fuzzy network analytic process can overcome uncertainties in the decision-making process, as well as the subjectivity and fuzziness of the evaluators for evaluation criteria, and solve the assumption that criteria are independent in the network analytic process, thus incorporating the interdependence and feedback of criteria into the decision-making process to provide a more efficient method for evaluators. The operating steps of the fuzzy network analytic process are shown in Figure 2 [14].

3.1.3. VIKOR Method. Proposed by Opricovic and Tzeng [15], the VIKOR method is one of the optimal compromise solutions in multicriterion decision making. Its basic idea is to define positive-ideal solutions and negative-ideal solutions. The positive-ideal solution refers to the optimal alternative according to the evaluation criteria, while the negative-ideal solution refers to the worst alternative according to the evaluation criteria. By comparing the closeness of each alternative to the ideal plan, the priority is determined according to the difference between each alternative and the ideal plan [16].

In calculating the closeness of each alternative to the ideal plan, the scores of all evaluation criteria must be added up. The summing method is developed from the Lp-metric of the compromise programming approach $[17,18]$, which has the characteristics of providing the maximum "group utility" and the minimum "individual regret of the opponent" in order that the compromise solutions can be accepted by decision makers.

The concept of the compromise solution of VIKOR can be expressed, as shown in Figure 3. As seen, $F^{*}$ is the ideal solution, $F_{1}^{*}$ is the ideal value of the first evaluation criterion, and $F_{2}^{*}$ is the ideal value of the second evaluation criterion. When the two evaluation criteria conflict with each other, in 


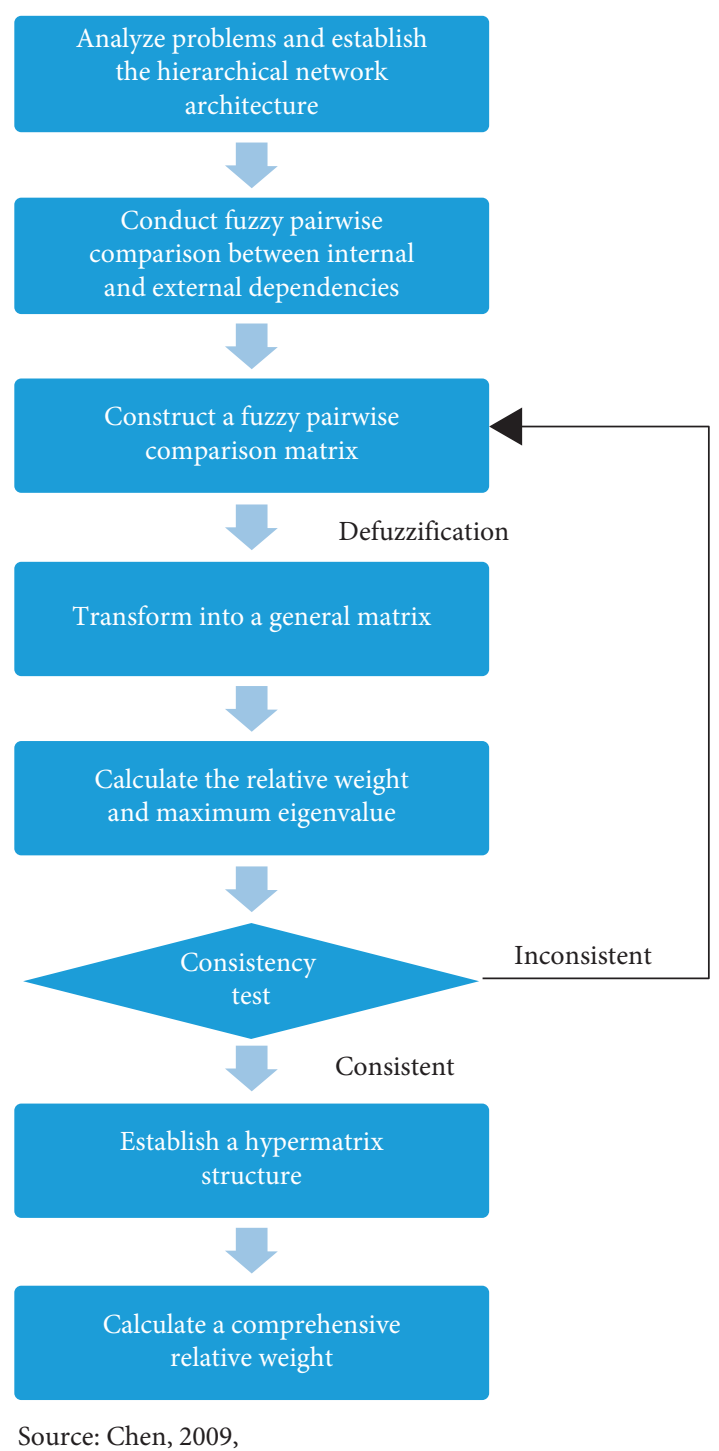

FIGURE 2: Operating steps of the fuzzy network analytic process.

order to achieve the ideal value of the first criterion, and vice versa, the performance value of the second criterion must be sacrificed. Hence, two conflicting evaluation criteria must make compromises to reach an agreement. The thick black circular arc line in Figure 3 is the noninferior solution set (compromise solution set) in this case. In this circular arc line (the region formed by the thick black circular arc is the feasible solution set), $F^{c}$ (comprised of 2 evaluation criteria: $F_{1}^{c}$ and $F_{2}^{c}$ ) is the feasible solution closest to the ideal solution $F^{*}$; thus, $F^{c}$ is the optimal compromise solution after compromise [19].

\subsection{Questionnaire Design}

3.2.1. Establishment of the Hierarchical Architecture of the Evaluation Criteria in the First Stage. Through literature review, this paper constructed the preliminary screening indices for supplier selection according to the five major dimensions proposed by Houshyar and Lyth [20], namely,

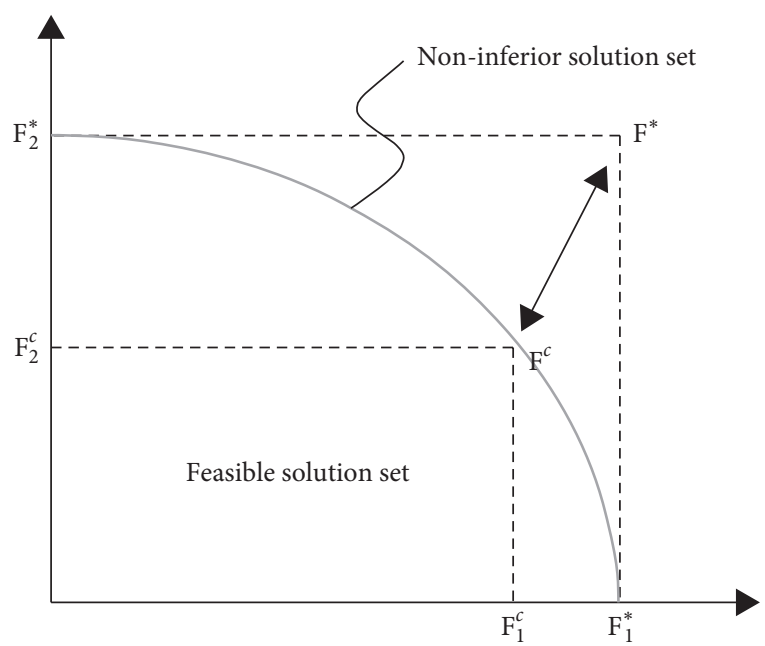

FIGURE 3: Diagram of ideal and compromise solutions.

cost benefit, performance, technology and competitiveness, relationship combination, and organizational structure, as well as the additional dimension of customer service, and retained those with the average above 5 points (including), based on the screening criteria used by Chen [21] to construct the hierarchical architecture of supplier selection for panel manufacturers. Then, according to the opinions of experienced procurement experts, the mutual feedback among the dimensions, and among criteria under the dimensions, is defined and represented by directional arrows in order to obtain the hierarchical network architecture of supplier selection, as shown in Figure 4.

\subsubsection{Design of the FANP Expert Questionnaire in the Second} Stage. According to the hierarchical network architecture, in order to obtain the expert opinions regarding relative importance, pairwise comparisons were conducted on all selection items to describe the relative importance of the two items. In terms of setting the linguistic values, Chen et al. [22] found that, in AHP evaluation, some scale values were significantly different from those originally defined. Hence, in terms of setting of scale values, the membership function values randomly generated in this paper range from 1 to $m$; that is, $l, m$, and $u$ are random. The correspondence between Saaty scale values and fuzzy numbers is shown in Table 2 [23].

3.3. Subjects and Data Collection. This study issued the questionnaires in 2 stages. The first stage was the evaluation index expert questionnaire, which had the purpose of establishing the hierarchical network architecture for this study. The expert samples must be professionals familiar with the procurement process and with 5 to 15 years of experience, as shown in Table 3 . The second stage was the FANP expert questionnaire. As this study intended to learn how the best candidates are determined when panel manufacturers are selecting suppliers, as shown in Table 4, experts of procurement departments in relevant industries were invited to complete the questionnaires in order to 


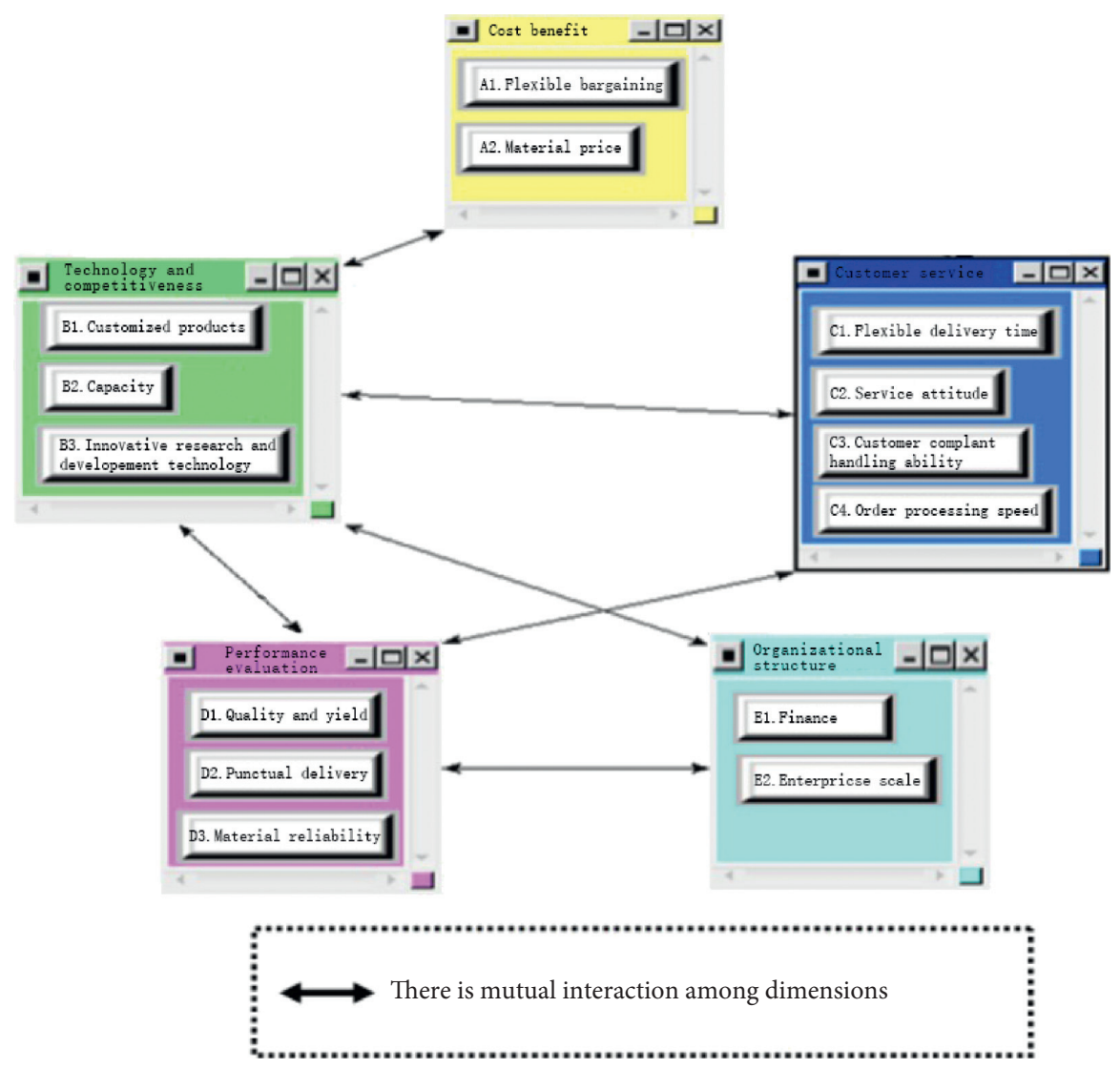

Figure 4: Architecture diagram of supplier selection.

TABLE 2: Correspondence between Saaty scale values and fuzzy numbers.

\begin{tabular}{lcc}
\hline Saaty scales & $m$ values $(1 \sim 9)$ & Fuzzy numbers \\
\hline Equal importance & 1 & $\widetilde{1}=(1,1,1)$ \\
Between weak importance and equal importance & 2.1 & $\widetilde{2}=(1,2.1,3.3)$ \\
Weak importance & 3.3 & $\widetilde{3}=(2.1,3.3,4.5)$ \\
Between essential importance and weak importance & 4.5 & $\widetilde{4}=(3.3,4.5,5.2)$ \\
Essential importance & 5.2 & $\widetilde{5}=(4.5,5.2,6.7)$ \\
Between very strong importance and essential importance & 6.7 & $\widetilde{6}=(5.2,6.7,7.3)$ \\
Very strong importance & 7.3 & $\widetilde{7}=(6.7,7.3,8.4)$ \\
Between absolute importance and very strong importance & 8.4 & $\widetilde{8}=(7.3,8.4,9)$ \\
Absolute importance & 9 & $\widetilde{9}=(8.4,9,9)$ \\
\hline
\end{tabular}

Source: Hsu, 2010, p13.

gather objective and integrated evaluations of supplier selection by virtue of their knowledge and expertise in procurement.

\section{Empirical Analysis and Results}

4.1. Analysis of Questionnaire Results. The questionnaire data were integrated in advance and conform to the consistency test. Analysis was conducted according to the process shown in Figure 2 to obtain the overall weight, as shown in Table 5 . It shows that "performance evaluation" is the most important, followed by "customer service," and the total weight of both is 0.576 , indicating that panel manufacturers pay more attention to suppliers' performance and customer service than other dimensions. As the parts and components of backlight modules are reusable and their costs are high, if the quality, materials, and services can be improved, costs can be reduced, and this result is consistent with the literature. In contrast, "organizational structure" has the lowest weight, which fully indicates that suppliers' finance and enterprise size have no significant influence on the perception of panel manufacturers. Therefore, in selecting suppliers, manufacturers should take organizational structure as a reference only and focus on other dimensions, such as quality, price, and technique. Suppliers can also improve their image and increase their fame in this way to improve their abilities. 
TABLE 3: Summary of titles and seniority of respondents in the first stage.

\begin{tabular}{lcc}
\hline Title & Number of people & Seniority \\
\hline Manager & 3 & $13 / 14 / 14$ \\
Chief & 4 & $8 / 10 / 10 / 12$ \\
Director & 8 & $6 / 6 / 8 / 10 / 10 / 10 / 12 / 13$ \\
\hline
\end{tabular}

TABLE 4: Summary of titles and seniority of respondents in the second stage.

\begin{tabular}{lcr}
\hline Title & Number of people & Seniority \\
\hline Assistant manager & 1 & 22 \\
Division head & 1 & 18 \\
Manager & 1 & 16 \\
Deputy manager & 3 & $13 / 12 / 13$ \\
\hline
\end{tabular}

TABLE 5: Overall weight of supplier selection.

\begin{tabular}{|c|c|c|c|}
\hline Dimensions & Evaluation criteria & Overall weights & Order \\
\hline \multirow{2}{*}{ Cost benefit (0.124) } & Flexible bargaining & 0.0466 & 13 \\
\hline & Material price & 0.0774 & 6 \\
\hline \multirow{3}{*}{ Technology and competitiveness (0.185) } & Customized products & 0.0328 & 14 \\
\hline & Capacity & 0.0779 & 5 \\
\hline & Innovative research and development technology & 0.0713 & 7 \\
\hline \multirow{4}{*}{ Customer service $(0.280)$} & Flexible delivery time & 0.0504 & 12 \\
\hline & Service attitude & 0.0318 & 3 \\
\hline & Customer complaint handling ability & 0.0818 & 4 \\
\hline & Order processing speed & 0.0540 & 11 \\
\hline \multirow{3}{*}{ Performance evaluation (0.296) } & Quality and yield & 0.1240 & 1 \\
\hline & Punctual delivery & 0.0666 & 8 \\
\hline & Material reliability & 0.1054 & 2 \\
\hline \multirow{2}{*}{ Organizational structure (0.118) } & Finance & 0.0622 & 9 \\
\hline & Enterprise scale & 0.0558 & 10 \\
\hline
\end{tabular}

Secondly, in terms of overall weight, the top 5 criteria are as follows: "quality and yield" (0.1240), "material reliability" (0.1054), "service attitude" (0.0938), “customer complaint handling ability" (0.0818), and "capacity" (0.779), indicating that panel manufacturers should pay attention to these evaluation criteria when selecting suppliers. It also indicates that quality is considered the most important, which is consistent with the results of many studies. In contrast, the bottom two are "flexible bargaining" (0.0466) and "customized products" (0.0328), indicating that there is little room for bargaining; thus, it receives less attention from panel manufacturers, and suppliers are unable to carry out customized production. Hence, suppliers must improve their competitiveness to enhance these 2 abilities.

4.2. VIKOR Analysis. In this stage, based on the relative weights generated by FANP, the VIKOR method with its characteristic of reaching compromise solutions was adopted to rank the backlight module suppliers. VIKOR is mainly used to deal with conflicts among evaluation criteria, produce the optimal compromise solution, and understand the gap between each supplier's performance and the positive-ideal solution or the negative-ideal solution. In this paper, $v$ was set as 0.5 . Through normalized calculation, the weights generated by FANP are used to obtain the positive- ideal solution or negative-ideal solution, the distance, and the synthesized indices, as shown in Table 6. Among them, Supplier D is the most appropriate and Supplier B ranks last.

The above results show that Supplier D is superior to the other three. According to this study, the reason is that the first consideration of panel manufacturers is quality in selecting backlight module suppliers, followed by delivery time and price, which is consistent with literature results. However, since Taiwan's accession to the World Trade Organization (WTO), enterprises are developing towards globalization. In addition, with the assistance of computers, networks, and other information technologies, information flow, logistics, financial flows, and service flows among enterprises have been integrated. In order to have considerable competitive advantages, suppliers should accurately know their information flow and have stable logistics, as well as financial flow with convenient transactions and service flow with resource integration; hence, Supplier D stands out. The VIKOR ranking method can reveal the relative positions of all suppliers and competitors and identify the gap between performance and the positive-ideal solution. In order to improve their market shares, all suppliers should use their advantages to improve their market competitiveness and continue to create their own characteristics. They 
TABLE 6: VIKOR evaluation results.

\begin{tabular}{ccccc}
\hline & A & B & C & D \\
\hline VIKOR & $0.362(2)$ & $1(4)$ & $0.478(3)$ & $0(1)$ \\
\hline
\end{tabular}

should also follow up and strengthen weak projects to create competitive advantages.

\section{Conclusion and Suggestions}

5.1. Conclusion. In today's intense global competition, the era when enterprises only emphasized product quality and price satisfaction has gradually passed; instead, contemporary competitiveness demands quality, price, service, delivery time, and technique. With the assistance of suppliers, enterprises can enhance their partnership with upstream, midstream, and downstream firms and shorten delivery and ordering time, which also effectively reduces product costs to improve customer satisfaction. However, in terms of supplier selection in Taiwan, enterprises' procurement is often affected by environmental factors or bargaining differences. Secondly, regarding multicriteria evaluation, it is usually assumed that the criteria are independent of each other; however, in reality, all criteria are connected and depend on each other. Hence, the FANP method is used in this paper to reduce the fuzziness and complexity of the decision problems, systematically identify the suppliers to be selected, and effectively eliminate the subjective preferences of decision makers. Finally, the weights obtained by the VIKOR and FANP methods are used to calculate the ranking of the four backlight module suppliers and highlight the gaps between ideal values.

According to the results of this study, the performance evaluation is higher than other evaluation dimensions, indicating the importance of quality and yield, material reliability, and punctual delivery; thus, suppliers must start with these dimensions to increase their market shares. Second is customer service, indicating that suppliers' service attitude, customer complaint handling ability, order processing speed, and flexible delivery affect their handling ability. Hence, suppliers should pay special attention to efficiency improvements and fast services to win the favor of panel manufacturers. Finally, in all the evaluation criteria, the weight of quality is the highest, indicating that quality must meet users' needs, which are measured by continuous process, product improvements, and customer satisfaction. Therefore, higher quality fitness indicates higher user satisfaction.

5.2. Suggestions for Future Studies. Based on analysis, enterprise buyers can understand the criteria, dimensions, and completeness of supplier selection in order to select suitable suppliers. It is suggested in this paper that future studies can be extended in the following directions:

(1) Regarding supplier selection, in addition to meeting the enterprise's needs, the customers' business philosophy should be considered and analyzed in order to develop better selection models.
(2) The business philosophies of different enterprises should be analyzed and integrated, as the analysis of a single enterprise is insufficient for completeness of supplier selection; thus, it is suggested that this industry should be considered for empirical analysis in future studies.

(3) With the development of information technology and the popularity of the Internet, the fuzzy evaluation model and execution procedure, as proposed in this paper, can be used to build the prototype of an online evaluation system in the future, which will reduce evaluation costs and time.

\section{Data Availability}

The data used to support the findings of this study are available from the corresponding author upon request.

\section{Disclosure}

The authors are solely responsible for this paper.

\section{Conflicts of Interest}

The authors declare there are no conflicts of interest regarding the publication of this paper.

\section{Acknowledgments}

This research was supported by following funds which the authors thank for: Guangdong Planning office of philosophy and Social Sciences Project (Youth): Research on crossborder social responsibility of private foreign trade enterprises in Guangdong and the Reconstruction of Legitimacy-Perspective of the Organization to piece together (Project Number GD20YGL09), Scientific Research Special Fund of Guangzhou Huashang College (Grant 2021HSDS02), Scientific Fund of Guangzhou Huashang College (Grant 2021HSDS29), and Department of Education of Guangdong Province "Innovative projects with characteristics of ordinary universities" project: Research on Sustainable Development of Foreign Trade in Guangdong Province Based on Emergy Footprint (Project Number 2019WTSCX158).

\section{References}

[1] G. W. Dickson, "An analysis of vendor selection systems and decisions," Journal of Purchasing, vol. 2, no. 15, pp. 28-41, 1966.

[2] C. A. Weber, J. R. Current, and W. C. Benton, "Vendor selection criteria and methods," European Journal of Operational Research, vol. 50, no. 1, pp. 2-18, 2007.

[3] S. Dowlatshahi, "Designer-buyer-supplier interface: theory versus practice," International Journal of Production Economics, vol. 63, no. 2, pp. 111-130, 2000.

[4] T. T. Barbarosoglu G, "An application of the analytic hierarchy process to the supplier selection problem," Production and Inventory Management Journal, pp. 14-21, 1997. 
[5] L. A. Zadeh, "Fuzzy sets," Information and Control, vol. 8, no. 3, pp. 338-353, 1965.

[6] A. Kaufmann and M. G. Madan, "Introduction to fuzzy arithmetic: theory and applications," International Journal of Approximate Reasoning, vol. 1, no. 176, pp. 141-143, 1985.

[7] L. A. Zadeh, "The concept of a linguistic variable and its application to approximate reasoning-I," Information Sciences, vol. 8, no. 3, pp. 199-249, 1975.

[8] L. A. Zadeh, "The concept of a linguistic variable and its application to approximate reasoning-II," Information Sciences, vol. 8, no. 4, pp. 301-357, 1975.

[9] L. A. Zadeh, "The concept of a linguistic variable and its application to approximate reasoning (part 3)," Information Science, vol. 9, no. 1, pp. 43-80, 1976.

[10] G. Klir and B. Yuan, Fuzzy Sets and Fuzzy Logic: Theory and Applications, Prentice-Hall, Inc., Hoboken, NJ, USA, 1995.

[11] H. J. Zimmermann, "Fuzzy set theory-and its applications II," Fuzzy Sets and Systems, vol. 3, pp. 396-397, 1991.

[12] T. L. Saaty and T. L. Saaty, "Decision making with dependence and feedback: the analytic network process," International, vol. 95, no. 2, pp. 129-157, 1996.

[13] G. Bueyuekoezkan, T. Ertay, C. Kahraman, and D. Ruan, "Determining the importance weights for the design requirements in the house of quality using the fuzzy analytic network approach," International Journal of Intelligent Systems, vol. 19, no. 5, pp. 443-461, 2004.

[14] G. W. C. Kaye, Using Fuzzy ANP for Technology Acquisition Analysis, National Chin-Yi University of Technology, Taichung, Taiwan, 2009.

[15] S. Opricovic and G. Tzeng, "Compromise solution by MCDM methods: a comparative analysis of VIKOR and TOPSIS," European Journal of Operational Research, vol. 156, no. 2, pp. 445-455, 2004.

[16] J. H. L. Ling and R. H. Legge, "Combine fuzzy integral and VIKOR model for evaluating airline service quality," Journal of Customer Satisfaction, vol. 5, no. 1, pp. 175-200, 2009.

[17] P. L. Yu, "A class of solutions for group decision problems," Management Science, vol. 19, no. 8, pp. 936-946, 1973.

[18] M. Zeleny and J. L. Cochrane, Multiple Criteria Decision Making, McGraw-Hill, New York, NY, USA, 1982.

[19] S. L. Su, Evaluating of Ground Crews of C-Airlines by Fuzzy Multi-Criteria Decision Making, Yuan Ze University, Taoyuan, Taiwan, 2010.

[20] A. Houshyar and D. M. Lyth, "A systematic supplier selection procedure," Computers \& Industrial Engineering, vol. 23, no. 1-4, pp. 173-176, 1992.

[21] Y. H. M. Chen, Approach for Evaluating the Banking Performance Based on the Perspectives of Balanced Scorecard, Kainan University, Taoyuan, Taiwan, 2005.

[22] C. P. Chen, C. Hsu, and G. R. Hus, "A study of the fundamental scale for pairwise comparisons in the analytical hierarchy process," Journal of Management \& Systems, vol. 16, no. 2, pp. 201-218, 2009.

[23] M. T. G. Hsu, Relational Analysis for Improving Unacceptable Consistency of Fuzzy Pairwise Comparison Matrices, Chung Yuan Christian University, Taoyuan, Taiwan, 2010. 